\title{
UCTM-An Ambidextrous Service Innovation Framework-A Bottom-Up Approach to Combine Human- and Technology-Centered Service Design
}

\author{
Wolfgang Vorraber ${ }^{1, *(\mathbb{D})}$, Dietmar Neubacher ${ }^{1}{ }^{\mathbb{D}}$, Birgit Moesl ${ }^{1}$, Julia Brugger ${ }^{1}{ }^{\mathbb{D}}$, \\ Sigmar Stadlmeier ${ }^{2}$ and Siegfried Voessner ${ }^{1}$ \\ 1 Institute of Engineering and Business Informatics, Graz University of Technology, 8010 Graz, Austria; \\ dietmar.neubacher@tugraz.at (D.N.); birgit.moesl@tugraz.at (B.M.); julia.brugger@gmx.net (J.B.); \\ voessner@tugraz.at (S.V.) \\ 2 Institute of Public International Law, Air Law and International Relations, Johannes Kepler University Linz, \\ 4040 Linz, Austria; sigmar.stadlmeier@jku.at \\ * Correspondence: wolfgang.vorraber@tugraz.at; Tel.: +43-316-873-8004
}

Received: 6 March 2019; Accepted: 16 April 2019; Published: 18 April 2019

check for updates

\begin{abstract}
Digital innovation is a key success factor for business enterprises and organizations concerned with public safety. Increasingly shorter technology cycles produce a stream of highly promising gadgets and smart devices and this innovative provision opens a gap between what is currently in use for the value-creation processes of an organization and what could potentially be used. The presented framework provides guidance on how to implement dynamic capabilities needed for business model and service innovation within a complex socio-technical system. A way to combine technology and use-case sensing with the ultimate aim of creating innovative artifacts for organizations is presented. While Business Model Innovation (BMI) literature mainly focuses on a strategic top-down process, we propose a bottom-up process-driven approach to complement business frameworks. Based on these insights, new service artifacts can be designed and analyzed in a systemic way. The applied research methodology is based on the design science research concept. A qualitative approach with focus groups was used to gather user requirements and facilitate participatory and user-centered design of information systems. In this paper, we provide a framework that supports business executives as well as IT experts on how to cope with and integrate new technologies into organizations, their processes, and their business models. In addition to a comprehensive theoretical overview of the proposed framework, we also provide practical results, since this framework was applied in the course of a service design and engineering research project. A use case of alpine rescue missions serves as an example to demonstrate the practical application of the proposed framework.
\end{abstract}

Keywords: socio-technical systems; information systems; systems engineering; digital innovation

\section{Introduction}

Continuous process improvement and digital innovation are crucial for business enterprises and for organizations concerned with public safety. Increasingly shorter technology cycles produce highly promising gadgets and smart devices opening a gap between what is currently in use in value-creating processes and what could potentially be used. In this paper, we provide a framework that supports business executives as well as IT experts on how to cope with new demands and integrate new technologies into organizations, their processes, and their business models.

While societal and regulatory developments constantly induce new requirements on information systems, technical developments often occur at an even faster pace. Increasingly shorter technology 
cycles result in highly sophisticated information technologies and enable opportunities for smart information services. Nevertheless, these changes lead to enormous challenges for sustainable IT operations and business management. In this paper, we introduce a use-case technology-mapping (UCTM) framework that fosters the elicitation of user needs, technology selection, and design of integrated and sustainable information service architectures.

In addition to introducing the service innovation framework, we provide practical results, as this framework was applied in the course of a service design and engineering research project in the public-safety domain. A use case of mountain rescue missions in the Alps serves as an example to demonstrate the practical application of the proposed framework. Building blocks of the UCTM framework have been created and validated in multiple domains during previous projects in the areas of health care, public safety, and automotive production [1,2]. The public-safety domain was chosen due to its special criticality in terms of process safety and security, and its special public outreach.

\section{Theoretical Background}

Before focusing on the proposed framework details, we review concepts and literature that form the basis for the framework. The first section deals with the theory behind socio-technical systems, which forms a key building block for the proposed framework. Digital innovation and created innovative artifacts always need to be seen in a socio-technical context. Based on the principle of joined optimization, a new service needs to be analyzed in a holistic manner incorporating social and economic aspects on micro and macro levels.

\subsection{Socio-Technical Systems}

Basic concepts to incorporate the technical and social aspects in workplace design already emerged in the 1950s in the domain of socio-technical systems and laid a foundation for research fields that evolved later [3-5]. A core concept of the socio-technical philosophy is that technical and social aspects of a system are interdependent and cannot be perceived separately. They can be seen as organized around functions. Socio-technical system properties emerge as a result of interactions between these human-technical functions. Another core principle is joint optimization, and this means that the socio-technical system must be optimized holistically. As a result, when focusing on a single aspect of the system, either technical or social, the system performance will degrade or even fail [6].

Work groups, whole organizations, or governments can be viewed as a socio-technical system. According to [7] socio-technical studies can be carried out on three interrelated levels: primary work systems, whole organizational systems, and macro-social systems. The distinctions between these levels are blurred, especially as there are many relations between them. A conceptual view of these socio-technical system levels is illustrated in Figure 1. The worker, or work group, is in the middle and surrounded by the socio-technical work system. This level encompasses the technology and tools to perform several tasks within a given environment and under organizational conditions. In a higher socio-organizational context, these conditions must be provided and integrated within the structure and culture of an organization. Finally, the whole organization is embedded in and connected with an external environment. As stated by [8] in the context of systems thinking, a holistic investigation of the socio-technical system is necessary to understand its underlying complexity and avoid the adherence of over simplistic cause-effect relationships. 


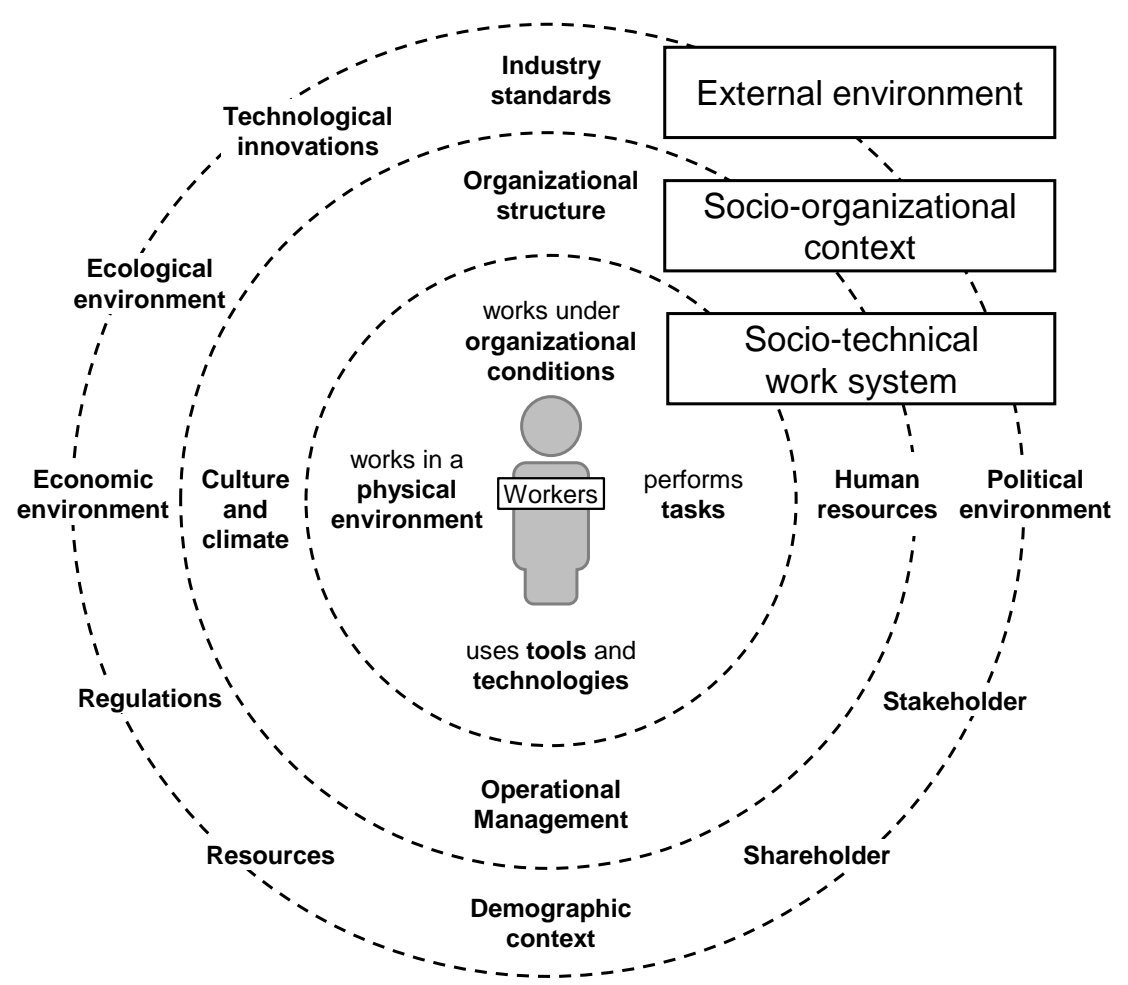

Figure 1. A generic model of socio-technical system levels based on [9].

\subsection{Research Fields for Analysis and Development of Socio-Technical Systems}

Various frameworks for service engineering and service design describe the ways and means of how to develop concepts and business models for innovative services. Service- and BMI may be triggered and controlled either from a strategic top-down or a more operational bottom-up approach. The latter are innovations that occur on an operational or process level and are then evolved on a more architectural and business model centered level (see Figure 2). In the domain of information systems in particular, various research fields deal with designing and engineering of systems and services in a bottom-up approach. We categorize them in general into:

- $\quad$ social science focused frameworks,

- classical engineering focused frameworks,

- design focused frameworks

and provide some examples for each of these.

As described by [5], research fields such as user-centered design (UCD), computer supported collaborative work (CSCW) and human-computer interface (HCI) have emerged during recent decades. These fields have their origin in social science. Social scientists bring in their expertise to software engineering and support the design of software systems resulting in these interdisciplinary research strands with a special focus on humans in the center of all considerations. Ref. [10] (p. 588) for example describe human-centered design as '[...] concerned with incorporating the user's perspective into the software development process to achieve a usable system.' CSCW especially focuses on workplace studies based on ethnographic approaches. Users, their interaction with artifacts, and the cooperation with other users, which is often based on tacit knowledge, is of special interest for these studies [11]. Studies are carried out in workplace settings such as control rooms, clinical settings or trading rooms [12-14]. The HCI discipline is more focused on building cognitive models of users of information systems [11] and therefore overlaps with user experience (UX) design discipline. The key term UX is defined as '[a] person's perceptions and responses resulting from the use and/or anticipated use of a product, system or service' [15]. Building on this, UXD discipline can be seen as '[t]he creation and synchronization of the 
elements that affect users' experience with a particular company, with the intent of influencing their perceptions and behavior' [16].

Whereas the framework presented here focuses on users and their needs, engineering focused frameworks (e.g., [17]) often focus on problems and the engineering of systems. Trying to solve a pre-defined problem may limit solution space in a very early stage. An engineering and a marketing perspective are part of product innovation. Following [18] (p. 1002) product innovation consists of two key tasks: 'physically make the new product [...] and sell that product to certain customers.' Both tasks were often considered separately, but in terms of new product development it is necessary to link customers and technologies [19]. Compared to products designing services faces the challenge that the service is much more associated with the usage [20].

The recently evolved discipline of service design builds on design thinking approaches and proposes a process for service creation [21,22]. A broad array of tools assigned to each phase of a service design process is described by [23]. Several these tools were developed or applied in the aforementioned research fields such as UCD, showing the overlapping character of these disciplines.

On the other hand, top-down approaches initially start from a business perspective and try to create services that provide net benefits for users. Research fields in this domain of strategic management and BMI build on a profound theoretical basis. As described in [24], among others [25] with his theories about innovation, and [26,27] with the theory of the resource-based view (RBV) of a firm, made major contributions to the field. Schumpeter [25] (p. 84) defined innovation '[...] as the setting up of a new production function', which can be interpreted as combining production factors in a new way. In her book 'The Growth of the Firm' Penrose [26] (p. 24) pioneered the RBV theory [27] and defined a firm as '[...] a collection of productive resources' [26] (p. 24), which are governed and guided by an administrative organization. These productive resources are used '[...] for the purpose of producing and selling goods and service' [26] (p. 24) and can be categorized into tangible things such as '[...] plant, equipment, land and natural resources, raw materials, semi-finished goods, waste products and by-products, and even stocks of unfinished goods' [26] (p. 24) and human resources of a firm. What is more, knowledge about how to seize these productive resources and the services they provide is essential for the economic sustainability of a firm [26] (p. 77). This knowledge about how to coordinate the resources can be seen as '[...] the essence of the firm and both the impetus and the constraint to its growth' [28] (p. 365). Here it is important to concentrate not solely on the internal knowledge of a firm, but also to include external knowledge such as market insights and technology into the knowledge base of the firm [26] (p. 77). This concept of developing knowledge of how to use the internal and external resources of a firm in a profitable way facilitated more recent BMI concepts such as the dynamic capabilities concept described in Section 2.3.

In the domain of business-focused frameworks, for example [29] provide the widely known business model canvas (BMC) to structure a business model in a highly abstracted manner, but which is easily communicated. Furthermore, the Value Proposition Canvas (VPC) supports the focus on and illustration of product properties and how they should fit to customer needs [30]. As stated by Chesbrough [31], tools such as the BMC are useful to visualize and explicate the basic logics of business models, but processes and an organizational structure need to be in place to foster and control BMI. Various modifications and refinements based on the BMC have been developed. Ref. [32] for example focus on the service-dominant logic of services created based on their canvas. Ref. [33] as well as $[34,35]$ provide canvases and methods especially targeted to start-ups and the social innovation lab canvas mainly focuses on social business models [36]. A recently emerging discipline, which brings together economic, social, and technical experts, is the 'New Business Models' community pursuing the goal to develop sustainable and socially acceptable business models often triggered or enabled by new technologies. This field is inspired by the idea to create holistic business models, which do not only focus on maximizing profit, but also includes social and environmental aspects to enable business models that meet long-term environmental sustainability goals and meet social needs of stakeholders and actors affected by the business [37-39]. This community is relevant for the work 
presented, since it also emphasizes a holistic and networked view on value creation as described by [40], but from a business level and a top-down driven approach. In this context, Upward and Jones [37] provide an ontology that supports the modeling of strongly sustainable business models. Their analysis clearly identifies gaps not covered by the BMC [29] regarding conceptual limitations and uncovered aspects of social and environmental viability of business models. As suggested by [37] the strongly sustainable business model ontology provides a profound basis for further development of tools, such as the strongly sustainable BMC [41] and the triple layered BMC [42], which are especially suitable for practitioners.

Overall, it is important to understand service innovation in a socio-techno-economic context. Viable service and business innovation jointly optimizes the fulfillment of user needs in a specific organizational context, which is again embedded and interrelated with a surrounding external environment. In the context of the presented UCTM framework, the term needs is primarily seen as a job or task specific desire for improvement from a personal or organizational perspective embedded in an STS. This desire may be based on a problem of an actor or an unexploited potential, similar to the concept of pains and gains visualized with the VPC [30]. Measures to fulfill these desires should be elaborated in a holistic way to provide a solution to the problem or to the unexploited potential while also including more general and basic needs as presented by Max-Neef [43]. Based on the concept of needs and satisfiers described by Max-Neef [43], the services and organizational concepts developed with the UCTM framework are intended to act as satisfiers to the needs identified initially. The, human, technical, and business aspects thus need to be considered in a holistic way.

In relation to the above-mentioned fields, the presented UCTM framework can be assigned to the field of user-centered service design and engineering in the intersection of the aforementioned bottom-up approach-based research fields. This framework considers socio-techno-economic aspects in a holistic way with a special focus on human-technology interaction in an organizational context.

\subsection{Dynamic Capabilities and Business Model Innovation}

The presented UCTM framework also considers the concept of dynamic capabilities as described by [44]. This concept states that BMI requires, among other activities, a constant process of sensing for new technical and process related opportunities for innovation and sees these dynamic capabilities '[...] as the foundation of enterprise-level competitive advantage in regimes of rapid (technological) change' [44] (p. 1341). Three interconnected process steps form the basis of dynamic capabilities: Whereas (1) Sensing focuses on opportunity scouting in technical and business aspects, (2) Seizing focuses on creating business models which implement identified opportunities and (3) Reconfiguration focuses on adapting or rearranging organizational structures to allow the innovations being realized and exploited.

Ref. [44] (p. 1324) stated in the context of BMI: 'Sensing opportunities and threats can also be facilitated if the enterprise and/or the entrepreneur explicitly or implicitly employ some kind of analytical framework, as this can help highlight what is important.'

The UCTM framework provides a bottom-up approach of the idea of dynamic capabilities in the form of a framework which covers both analysis of the technical possibilities that arise, as also constant monitoring of process related areas of improvement. As depicted in Figure 2, the UCTM framework focuses on business process and end user's needs analysis to create artifacts and improve value-generating processes to consequently provide a basis for new or adapted business models, whereas BMI as described by [44] follows a more strategy- and management driven top-down approach.

The presented framework facilitates continuous sensing of processes on workplace, organizational and external environment level (see Figure 1) combined with continuous technology sensing and assessment. Results of these sensing activities are then transformed into concrete service concepts which are consequently analyzed in accordance with legal, business, organizational, and social aspects. The UCTM framework is intended to complement existing top-down approaches by providing an informed base of knowledge of user's jobs and processes resulting in the design and 
implementation of an innovative digital artifact. The service concept of this artifact is analyzed from multiple socio-technical aspects. By analyzing the value network of the designed IT service, resource-based aspects such as capabilities, assets and partners, and values exchanged are considered. This complements other, more strategy focused frameworks [29,32,44]. Furthermore, the $\mathrm{V}^{2}$ value network tool [2] provides a basis for legal analysis. The UCTM framework is based on a similar idea as described by [22] who combined aspects of design thinking, foresight techniques, and dynamic capabilities for service-dominant logic businesses to a general framework, but provides a more bottom-up approach.

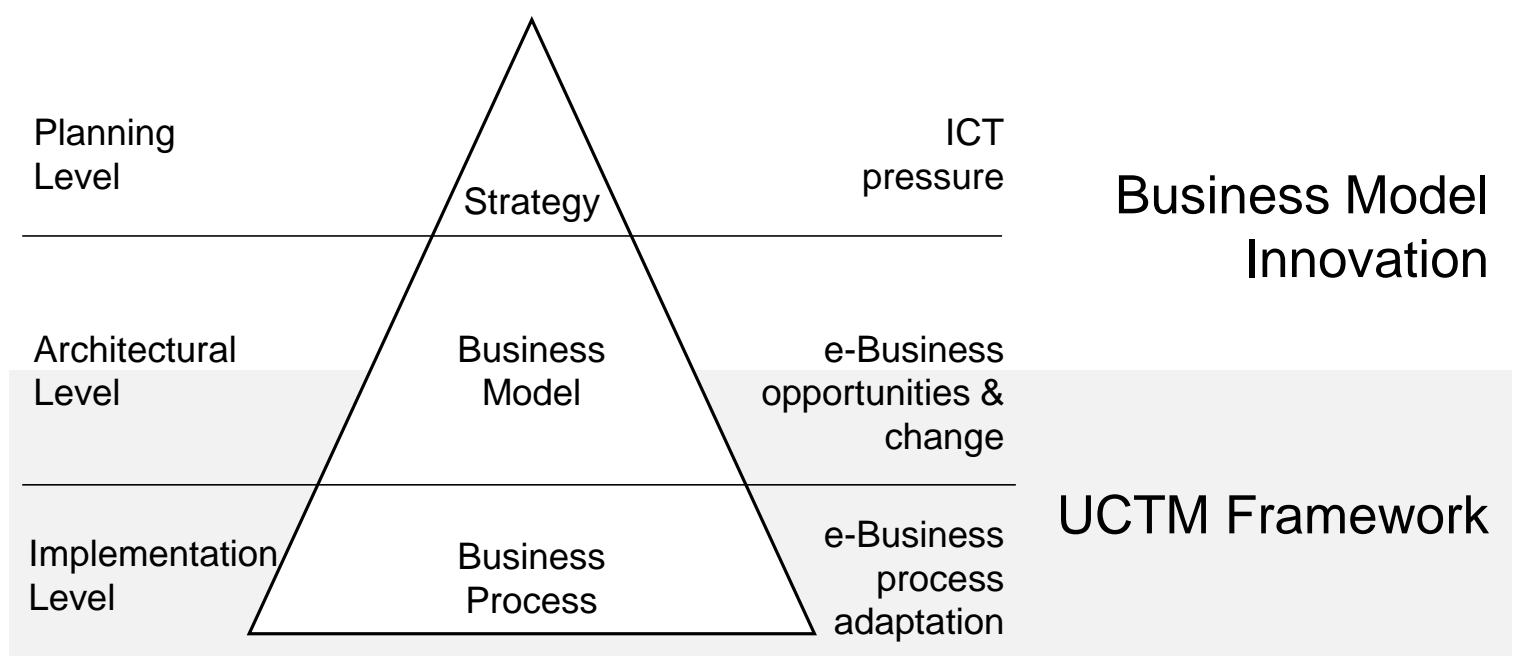

Figure 2. The UCTM framework in the context of Business Model Innovation visualized on the business model triangle of [45].

\subsection{Methodology}

The applied research methodology is based on the design science research concept described in [46]. Following this concept, our aim is to add to the knowledge base by developing/refining a method for designing socio-techno-economic systems in a holistic way. Furthermore, we applied this UCTM framework in various business environments such as health care, automotive production and public safety. A case from the public-safety domain serves as an example to show the implementation of this method by analyzing and designing an information system with critical social and organizational aspects. The application of the presented method in a real-world environment and the resulting artifact serves to validate the framework and to show its relevance. A close look at the UCTM framework and an overview of system analysis and service design steps is provided in this paper. Further detailed descriptions on service analysis and engineering aspects of the framework are planned for future publications. The remainder of this paper is structured as follows. Section 3 introduces a service innovation framework to support management and integration of smart technologies in large organizations. This framework is then applied in the case study described in Section 4 closing with results and discussion in Section 5.

\section{The Use-Case Technology-Mapping Framework (UCTM)}

\subsection{Basic Overview and Key Concepts of the UCTM}

Recent IT developments in the domain of smart devices and smart data promise digital innovation potentials for business enterprises as also for organizations concerned with public-safety management. Decision makers and IT experts are often confronted with the questions of, which technologies may best improve which processes and how this new technology may be integrated into existing or new 
business models. The presented service innovation framework (see Figure 3) is intended to serve as a guide through the process of use-case and technology identification, selection, and implementation. A first version of the basic framework was applied in the health care area. At that time, it was used to guide the information service development of an augmented reality application based on Google Glass to support surgeons during interventions [1]. Furthermore, an earlier version of the framework also guided several students in their master's thesis work on designing smart services in automotive production. While the framework and concepts behind the framework persisted, the tools that were used in analysis and design steps were adapted to the specific application domains. This paper presents tools for the public-safety area.

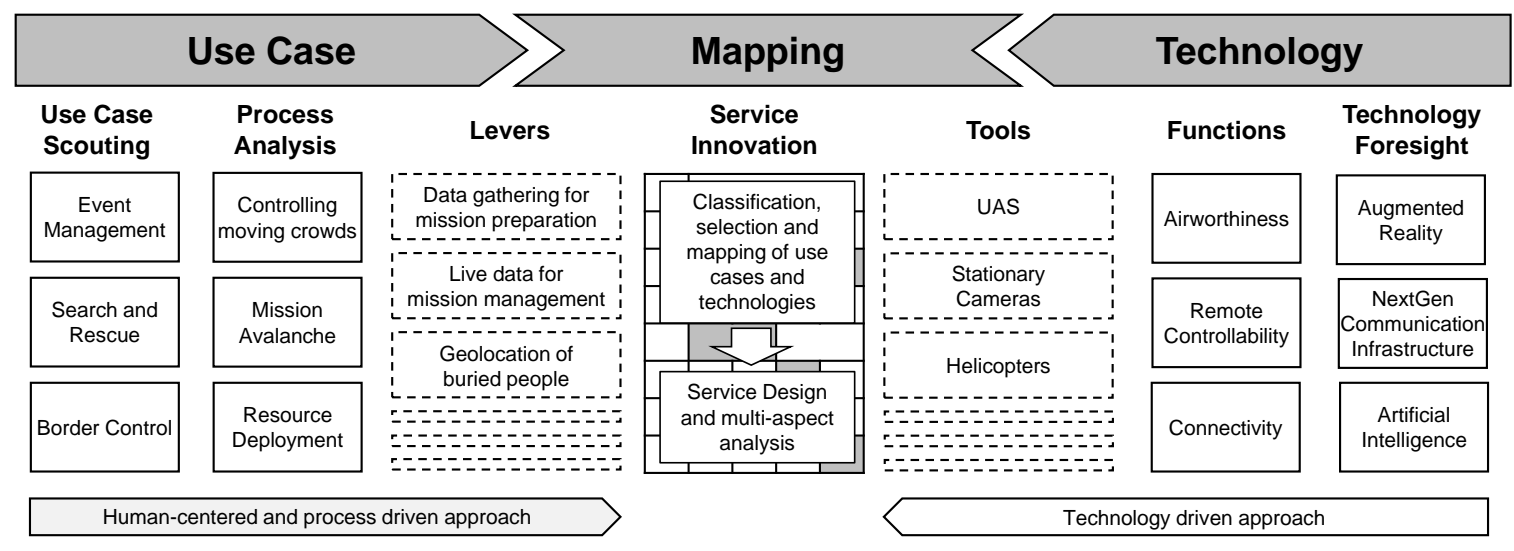

Figure 3. Use-case technology-mapping (UCTM) Framework.

\subsubsection{Basic Framework Concepts}

The arrows at the bottom of Figure 3 depict the two underlying concepts of UCTM:

- Human-centered and process-driven approach (left side): This concept includes requirements engineering and human-centered analysis to identify the needs of individuals or organizations.

- Technology-driven approach (right side): This approach goes back to the Schumpeterian concept of innovation in the sense of combining existing factors of the production function in a new way [25]. Therefore, the aim is to analyze current and anticipate future technological developments and to take these results as a starting point for exploring possibilities to create tools and services that meet user needs.

As indicated by the human-centered and process-driven arrow, process analysis and requirements elicitation for areas of improvement could initially drive the innovation process by following the use-case-triggered path. Likewise, technology scouting and assessment of possibilities enabled by new technologies, represented by the technology-driven arrow, could be the driving element for new processes and use cases. This would be described by the technology triggered path.

Both concepts are highly relevant as also pointed out by [44] (p. 1327) who stated: 'Business models implicate processes and incentives; their alignment with the physical technology is a much-overlooked component of strategic management. The understanding of the institutional/organizational design issues is typically more limited than the understanding of the technologies themselves.' The presented framework addresses this important aspect by providing a bottom-up approach starting on a process level (see Figure 2) and therefore ensures understanding of the process and the technology aspects. This ensures a deep understanding of the mentioned processes and incentives and forms a solid basis for BMI from a managerial perspective. Consequently, BMI may build on the insights gained through this approach. As stated by [44] (p. 1330) successful business models need to '[...] be astutely crafted. Otherwise, technological innovation will not result in commercial success for the innovating enterprise.'

The presented framework interlaces the requirements for the user-driven and technology-driven approaches, resulting in three concurrently and iteratively executed main process steps illustrated 
at the top of Figure 3. The needs of users or an organization, represented by the Use-Case arrow, and existing or upcoming technological possibilities, represented by the Technology arrow, should be mapped to create innovative and beneficial services (Mapping step).

Depending on which process phase is initially executed, the service design and innovation process is initiated by the user-driven, or technology-driven approach.

\subsubsection{Use-Case Phase}

As indicated by the process step on the upper left of Figure 3, user needs and corresponding areas of improvement in their organizational or personal context need to be identified. A continuous process of use-case scouting tries to identify areas with specific relevance for an organization or user. Criteria for relevance depend on the domain in which an organization is active. For commercial organizations, relevance can for example be a high impact on business success, whereas positive societal impact may be more relevant for public-safety organizations. Furthermore, use cases can also be selected in an informal way based on the experience and tacit knowledge of experts. The identified areas are represented by use cases to create a more tangible method for communicating with stakeholders. A detailed analysis of representative processes of these use cases is then conducted with the aim of identifying areas of improvements. During this step, the needs of actors and possible improvement potentials are identified. These improvement potentials are then formulated as so-called improvement levers.

\subsubsection{Technology Phase}

The process step at the top right of Figure 3 represents a continuous process of technology foresight and technology scouting, followed by categorization and assessment of technologies which could be relevant for service innovation in an organization. Technologies can be tangible (e.g., new end devices such as optical head mounted displays), intangible (e.g., new knowledge in form of artificial intelligence and data analysis methods) or a combination of it. Technology foresight can be based on strategic analysis of upcoming developments which could be relevant for the organization at hand.

Based on the technology foresight, various questions can be asked by following one of the prescribed paths:

- Technology triggered path: What functionality does technology offer and how could this functionality or a combination of various functionalities be used to meet basic/general customer needs (e.g., a time- and location-independent knowledge exchange). The availability of new tools can be a trigger for process adaptation or innovation.

- Use-case-triggered path: How could this technology or a combination of it be used to support the implementation of identified improvement levers, which were determined in the use-case phase?

Both the main process steps use-case identification and technology scouting should be carried out continuously and iteratively and should ultimately lead to the mapping procedure in the center.

\subsubsection{Mapping and Design Phase}

During the mapping step, service concepts are created, which combine the most promising use cases with the best fitting solutions. Primarily, this step focuses on mapping technology, which was scanned before with needs described in use cases. Nevertheless, this mapping procedure also allows generation of alternative solutions with only limited technology share (e.g., mainly organizational changes supported by technology). The fitting process is a combination of extracting and ranking needs and assessing how functionality offered by the scouted technology may fulfill these needs. Resulting fits are then transformed into service concepts serving as a starting point for the service design and engineering process.

A first concept of the intended service is created and evaluated with respect to legal, organizational, and business aspects. Here conceptual modeling of key aspects of the service is used at an early stage 
to analyze effects on the targeted processes and consequently on the business model. For business as well as legal aspects, modeling tools such as value network analysis and special extensions for legal assessment may be used [2]. The evaluation of business design is an integral part of a successful innovation as also emphasized by [44] (p. 1327): 'Indeed, there is considerable evidence that business success depends as much on organizational innovation, e.g., design of business models, as it does on the selection of physical technology.' While pointing out the importance of analysis of the designed service on process as well as business model level (see Figure 2), this article focuses in particular on process level innovation which consequently may result in BMI.

The following section describes the outlined main process steps in a more detailed way. The presented tools are generally applicable for both mission-driven and business-driven organizations. Nevertheless, detailed aspects such as context-sensitive questions during the presented process analysis embrace special needs of large mission-driven organizations in public-safety management, which need to be adapted when used in other contexts.

\subsection{Requirements Analysis Process and Analysis Tools}

This phase ensures the identification of the most relevant user processes, the analyzing of these processes with various ethnographic and formal tools and jointly identifying areas of improvement. The results of this process provide a good overview of the pains and gains (see [30]) of the processes used by an organization or a user. The following requirements analysis process is based on tools and concepts developed in previous projects [47,48], which were enhanced and refined in the course of this manuscript. Each step and corresponding tools will be described according to the sequence in which they are typically applied.

\subsubsection{Identification and Categorization of Process Types}

The goal of this step is to identify and categorize use-case-related processes, which are then analyzed in greater depth. Depending on the domain, this could be relevant user jobs or tasks, or as in our case, public-safety organization mission types.

\subsubsection{Rating of Relevance of Process Types}

In a next step, the identified processes need to be rated to ensure that further analysis is restricted to relevant cases only. Again, the rating is domain-dependent and individual for the project at hand. Typical rating criteria are frequency of process execution and importance for a company's or personal value creation.

\subsubsection{Detailed Process Analysis}

Based on the relevance rating, highly relevant process types are selected and analyzed in more detail. Various ethnographic (e.g., shadowing) and formal process analysis tools (e.g., BPMN, UML, etc.) can be used. The goal of this step is to understand user processes, and then to jointly identify areas of improvement with the user. The pitfalls and areas of improvements obtained in the course of this work are then analyzed, classified, and rated in collaboration with experts of the focus group. These findings provide a basis for the following step of lever generation.

\subsubsection{Generation of Levers}

The metaphor of a lever is used to label generally formulated means, which support the realization of identified areas of improvement. These levers are formulated in a non-technical sense. This is a very important but also difficult point, especially for technicians, since it requires the avoidance of thinking in technologies at a too early phase, and omitting solutions as a result. These levers are then instantiated into practical measures which should have the effect of avoiding or overcoming the identified pitfalls. 


\subsubsection{Identification and Selection of Means to Implement Identified Levers}

There could be various methods for establishing practical measures to overcome the identified pitfalls and implement the specified levers. Possible solutions may be organizational changes, process changes, implementation of technical artifacts to support processes or a combination of them. All possible and practical solutions are summarized and specified on concluding this step. Since this is not a trivial task, the UCTM framework provides guidance for this step (see the following Section 3.3).

\subsection{Technology Analysis, Selection and Mapping}

The process step technology analysis can either start in an informed state due to previous requirements elicited in the use-case analysis process step, or based on a green field approach. In the latter case, existing or upcoming technologies are abstracted to the functionalities they are providing. These functionalities are subsequently taken as a basis to create functionality-bundles which could provide special benefits for potential user groups (e.g., public-safety organizations). This may result in technology combinations or may serve as a starting point for technology innovation. Alternatively, in the informed state areas of improvements, corresponding improvement levers and the required functionalities are already identified. In this case, existing or upcoming technologies are abstracted and matched with the required functionalities. Again, opportunities for technological innovations may be identified in this mapping step which could be further explored in another process iteration.

As stated in the section above, process changes, organizational changes, creation of technical artifacts, or combinations of them may be required to realize the improvement levers. A special focus of this step is thus placed on how to identify and select the best technology for the identified use cases. A quantitative approach ensuring the participation of a broad expert base is proposed, to make this selection process in a transparent manner. This approach is based on the concept of value-benefit analysis and starts with defining properties specifically relevant for use cases in close collaboration with experts. One example for relevant properties is provided in e.g., spatial coverage of sensing technologies. Furthermore, a weighting scale defining the importance of these properties is created. Different technologies selected during the technology-scouting phase are then assessed based on this scheme resulting in a value-benefit ranking of technologies. This ranking is then taken as an input for the UCTM process step, where possible positive side effects caused by the use of selected technologies are also considered to be decision criteria resulting in a final decision on which measure (e.g., technology) fits best in order to implement a specific improvement lever. Alternatively, tools such as the VPC and alternative rating methods may be used in collaborative workshop settings with experts to select appropriate combinations of measures.

As stated by [44] (p. 1326) from a BMI strategic perspective, 'once a new (technological or market) opportunity is sensed, it must be addressed through new products, processes, or services'. Therefore, a first concept of the intended service is created and evaluated for legal, organizational, and business aspects. Legal and in a further step social analysis is especially important, since not everything which is technically feasible and commercially sound holds good from a legal perspective. A legal evaluation of the selected use case-technology combination based on the concept introduced in [2]—is thus of the utmost importance. In short, for each use case all value exchanges between actors of the underlying value and information exchange network are assessed according to legal regulations. Each exchange relation is rated on a three-level scale analogous to traffic lights reaching from compliant to existing legal regulations (green light), to minor actions (e.g., notification to data protection board) required (yellow light) up to legal regulations need to be amended to permit value exchange (red light).

\section{Case Study}

This section provides a case study applying tools and concepts described in the previous section on a real-world case elaborated with experts from the Austrian Federal Police. According to the IS 
research framework of Vidgen and Braa [49], the following use case can be categorized as a 'soft case study', as it is used to gain an in depth understanding of the actual situation. During the study, information was acquired through interviews, desk research, participation, and inspection of several technical documents.

\subsection{Case Introduction}

Figure 4 provides an overview about the case study steps and corresponding paragraphs. The case study starts in a pre-informed state, where areas of interest (e.g., rescue mission, border security and management of large-scale events) were pre-defined during the project bid phase.

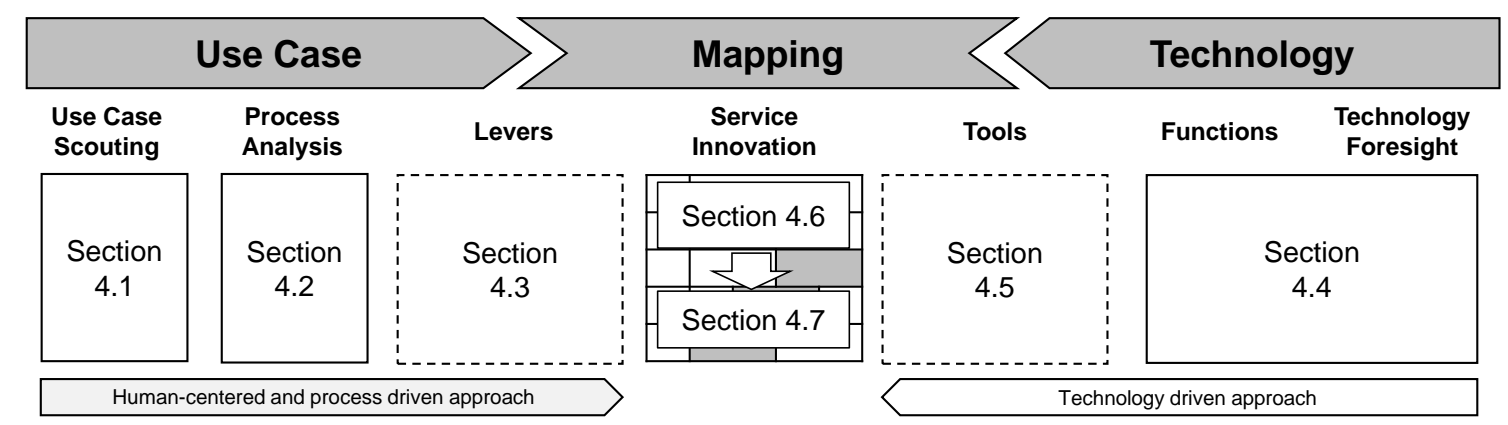

Figure 4. Case study steps and corresponding paragraphs.

\subsection{Process Analysis}

An initial categorization of mission types for all use cases is generated, to obtain an overview of different types and characteristics of various missions and to create a shared picture of the context of these missions. Criteria for identifying different mission types are for example the kind of organizational structure (e.g., [50]) needed to manage the mission (e.g., daily operation mode or special organization) or spatial characteristics of the mission.

Based on knowledge gained from a previous project and a focus group discussion the following mission types for mountain rescue missions in the Alps have been identified:

- $\quad$ avalanches

- alpine accidents (e.g., climbing accidents, canyoning, etc.) without search missions

- $\quad$ search missions.

Data about past missions from statistics, official reports, and expertise of focus group members was collected for the case study at hand. Mission properties such as number of occurrences, number of injured and dead people, costs of damage, and usage of mission resources in respect to human and non-human resources are used to structure data analysis and to create an objective rating of relevance for the previously identified mission types. Analysis revealed that avalanche missions are highly resource intensive but unlike mountain accidents, do not occur with great frequency. Since both mission types have a high relevance and search missions are often a part of both the other mission types, the first two mission types were selected for investigation in more detail.

In a next step representative processes for mission types need to be analyzed in close cooperation with experts who have ideally been part of the mission. The involvement of mission participants together with an open communication culture, which facilitates identification and discussion of problems occurring in the course of these missions are essential to these workshops. This provides the opportunity to elicit areas for improvements in communication flows, organization, processes, or other areas of a mission. Analysis not only covers the mission phase, but also considers the preparation and post-mission phase.

A process analysis notation, which is especially suitable for a domain expert workshop is used. As depicted in Figure 5, the used analysis tool (a first version of the tool was presented by [47]) 
structures mission participants vertically and their core activities horizontally according to their sequence in time. In contrast to primary activities, supportive activities are indicated by a dotted line. Human communication flows (curved arcs) and data exchanged between information systems (straight lines) are illustrated vertically and connect activities. A special focus is placed on potential interruptions during these connections or problems in executing essential activities. The basic colors (blue for activities, orange for communication and green for information) illustrate processes that are working well, whereas red always indicates flaws or possible problems. Finally, supportive communication and information links can be illustrated by using dotted lines. To keep the process model simple, however these assisting connections are often omitted, as they are commonly uncritical. On top of the model, major state changing events are outlined to highlight milestones or phase transitions during a mission. At the bottom, these phases are summarized and named. In general, missions of this kind can be divided in at least three different phases-a preparation, the mission, and a post-processing phase.

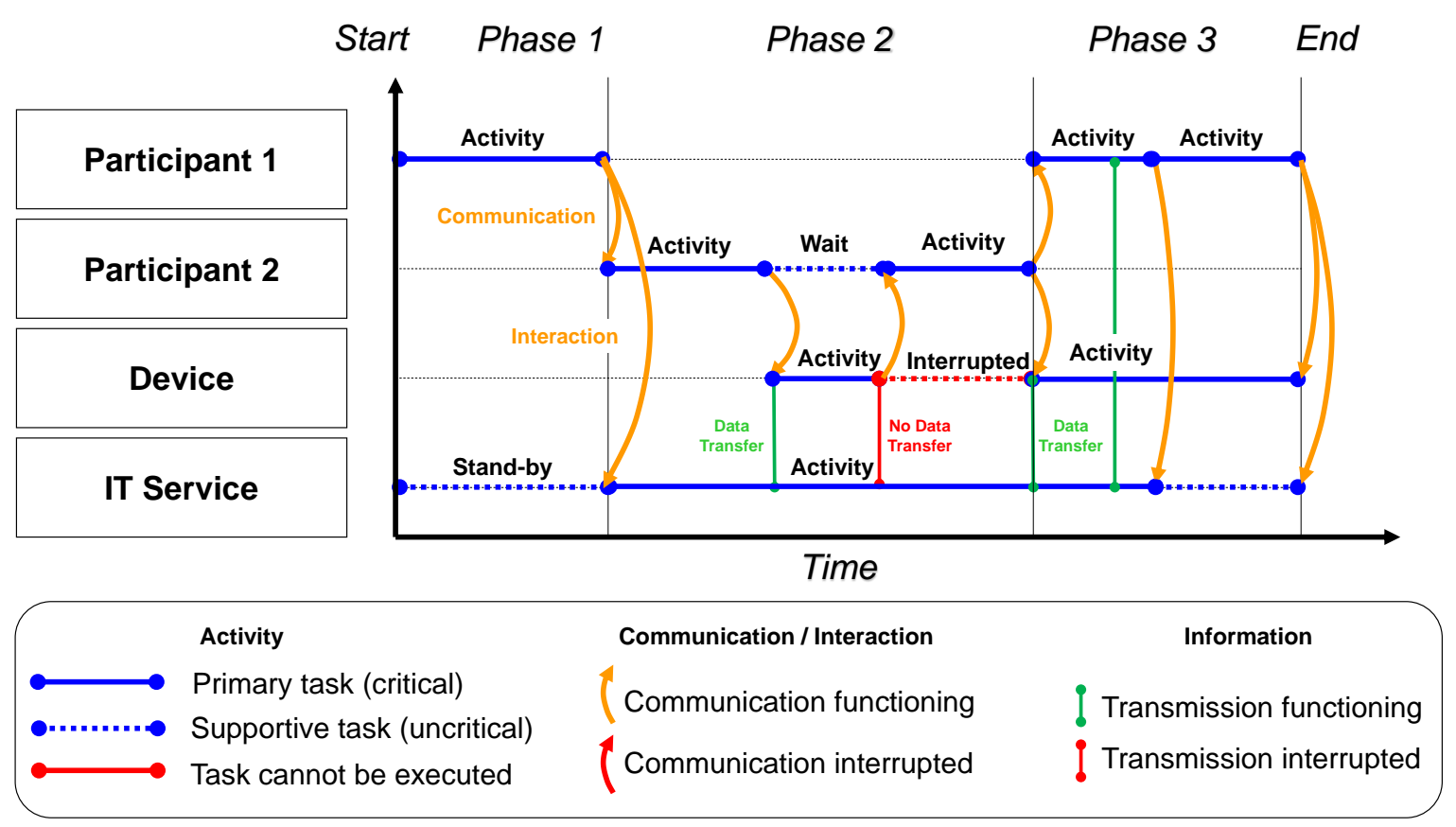

Figure 5. Notation of the process analysis tool.

To gather all relevant elements within this process, the following aspects are discussed for each phase [51]:

Which information is needed in the respective phase?

- What is this information needed for?

- Who needs this information?

- When/how often is this information needed?

How is the information obtained?

- How is the information flow initiated?

- Who provides the information?

- Which medium is used for information exchange?

Figure 6 provides an example of communication analysis for an avalanche rescue mission. What became obvious in the course of this analysis step was that helicopters used for transportation as also for search and mission management are of very great value as support for these missions. Unfortunately, helicopters are frequently unable to provide this valuable support due to bad weather 
conditions (e.g., fog) in the area of interest, or also at their take-off sites. The range of view for pilots is essential for take-off permissions. Volatile weather situations in alpine regions often impede the use of helicopters. The loss of helicopter support significantly complicates search and rescue missions and may also increase risk since equipment and rescuers must be deployed based on terrestrial means of transportation or even without any transportation whatsoever. This and further aspects in the domain of search tasks open up areas of improvements which are specified and summarized with the improvement levers concept elaborated in the next analysis step.

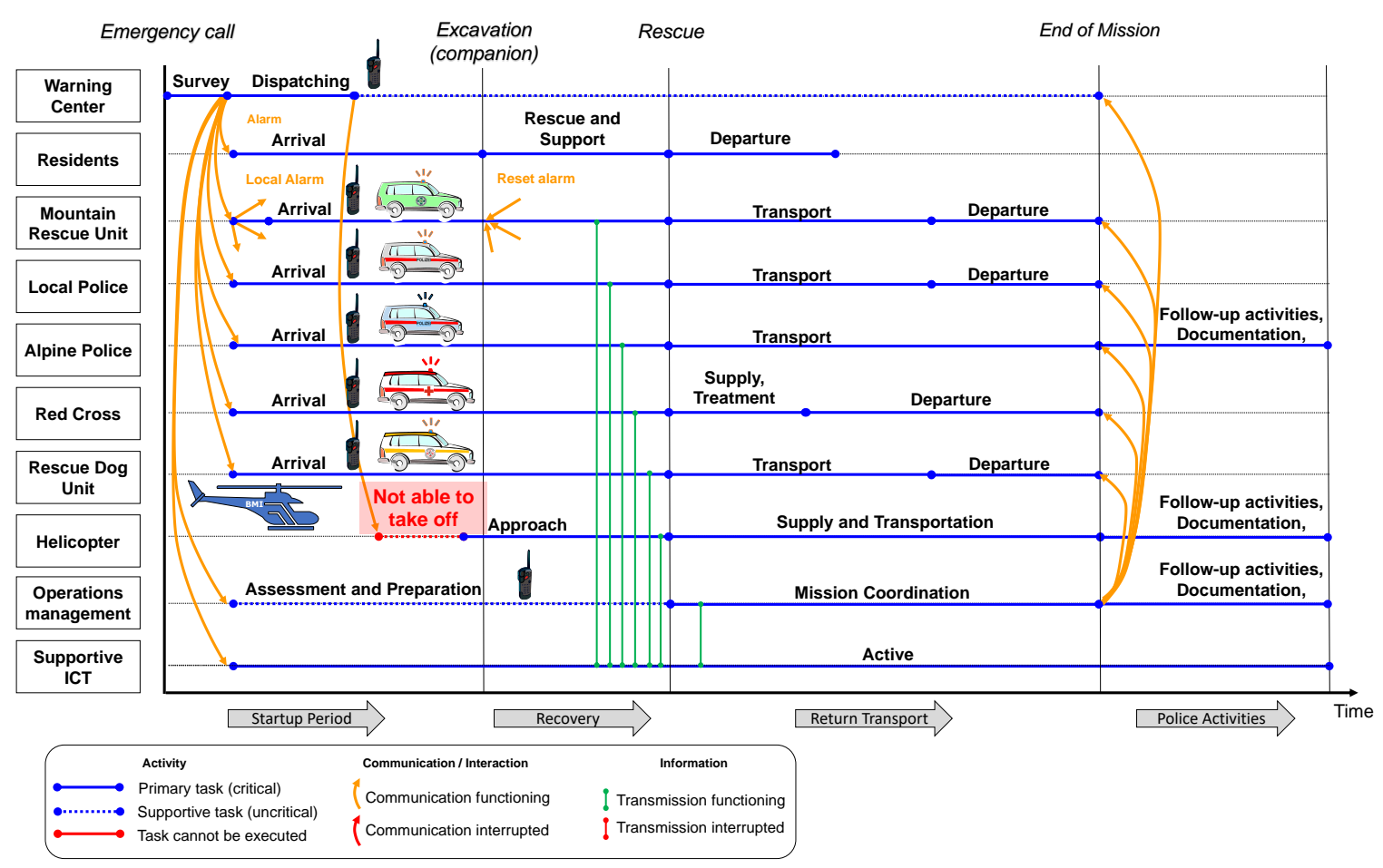

Figure 6. Communication process analysis of an alpine avalanche rescue mission.

\subsection{Identified Improvement Levers}

The following improvement levers were formulated based on identified areas of improvement.

\subsubsection{Provision of Current On-Site Location Information}

When creating the first operational picture, e.g., directly after the emergency forces reached the avalanche site, communication with the mission control center is based on audio-only radio systems. As a means of obtaining an improved situational overview it would be interesting and helpful if the incident commanders were to be provided with live pictures from the deployment area.

\subsubsection{Support for the Definition of the Search Area}

- Avalanche deposit area

- Potential detection areas

The definition of the search area in the event of avalanches and general search and rescue missions is of the utmost importance. Especially in cases where persons are missed in relatively large search areas such as an entire valley and information about possible search areas is sparse, support for the definition of the search area may have a high impact on the efficiency of a search and rescue mission. Currently, helicopters as a means of transportation for technical as well as human search resources may provide important information to define the primary search area. This could result in a more precisely defined search area facilitating deployment of rescue forces to the primary search area. The search range and thus search time could consequently be reduced, which in turn could lead to an immense 
increase in survival chances especially in avalanche incidents. Since the operation of helicopters is frequently not possible, an alternative carrier for aerial sensors may improve this initial process of search and rescue missions. The rapid exclusion of unnecessarily searched terrain and the associated massive time gain would be the major advantages of this utility lever.

\subsubsection{Extension of Search/Visual Field of Search Staff}

Alpine search missions must often be conducted in very rough terrain. A search for missing persons in glacier crevasses or caves, as also in other hard-to-reach areas (such as on the far side of a torrential river that is difficult to cross) can not only be very time-consuming, but also dangerous for the deployed forces. Furthermore, the search for missing persons at increased avalanche warning levels is associated with high risk of the emergency personnel and requires an accurate assessment of the operational picture, which can even lead to the suspension of the search and rescue mission. A possibility to extend the field of vision of search and rescue staff would increase both the efficiency and the safety of rescuers.

\subsection{4. (Partially) Automated Search for Casualties/Buried Victims}

After an avalanche alarm the response team tries to locate the avalanche deposit area as fast as possible. This is a resource-intensive activity since detection tools are used manually and carried by rescue team members. A (partially) automated search enabled by artifacts which may carry sensors may speed up search processes and again increase the safety of the rescuers by preventing them to access potentially dangerous areas.

\subsubsection{Airborne Search}

In many mountain search and rescue activities, a helicopter is indispensable due to the speed and the bird's eye view it provides. If the helicopter is unable to start or enter the suspected accident area due to bad weather, the response team must resort to a purely terrestrial search. An alternative way to provide an aerial view on the area of interest, which can operate in fog, rain, snowfall, and wind would potentially speed up the search process.

\subsubsection{Support of Documentation Work}

Once a rescue mission is completed, it must be adequately documented. For this purpose, it is sometimes necessary to have the routes that were used by the injured mountaineers re-climbed or hiked by professional climbers or police personnel. In the case of avalanches, the avalanche deposit area must be measured subsequently, which includes the documentation of all points of interest in this area (e.g., location of the buried persons).

A (semi-) automated documentation process enabled by birds-eye views on the area of interest may speed up the documentation process and save human resources otherwise used for time-consuming manual documentation. Furthermore, replacement of human resources potentially also increases safety for these personnel, since they do not need to move around in volatile alpine environments and expose themselves to various risks (e.g., rockfalls, avalanches, etc.).

\subsection{Technology Foresight and Function Definition}

Since the presented use case is embedded in a real-world public-safety project, technology foresight started in a pre-informed state where first focus was already laid on airborne technology. The following general functions must be provided by this technology:

- provision of an aerial view of the mission area

- remote controllability

- $\quad$ operable in bad weather conditions (wind, fog, rainfall, etc.)

- $\quad$ operable in the dark 
- operable in a broad temperature range, with the focus on low temperatures.

In addition to these general functions, further airborne functions should be provided. The technological equipment should be capable of flying along pre-defined routes, on a defined offset above ground and should be able to hold a position for a prolonged time period. Furthermore, the platform should be able to carry one or a combination of the following sensors and communication infrastructures:

- Sensor to identify persons within or close by an avalanche (Avalanche transceiver, avalanche radar, metal detector, mobile phone localization detector, etc.)

- Infra-red and video camera

- $\quad$ Positioning system (e.g., GPS), compass

- Mobile TETRA base station for wireless communication infrastructure

- Sensor required to be able to navigate within caves

\subsection{Tool Analysis}

As a technical instantiation covering most of the identified levers, an aerial platform, which can accommodate various kinds of sensors, was identified. Data generated by these sensors should preferably be transmitted in real time to respective data sinks. Furthermore, the flight platform should be controlled automatically, but also manually in an intuitive manner. Above all, the system should be integrated into the backbone IT-infrastructure of the mission-driven organization to be operable with high availability and reliability.

This first set of requirements form the basis for technology scouting and more concrete definitions of possible technical instantiations of the improvement levers as also a first legal assessment. Since an aerial platform capable of carrying various sensor types is the selected technical means for implementing identified improvement levers in the project, the following subsection provides definitions and an overview of different possible technical instantiations.

\subsection{UCTM and Service Design}

As described in Section 3.3 process changes, organizational adaptation, creation of technical artifacts, or a combination of these aspects is needed to implement identified improvement levers. The improvement levers listed above could primarily be implemented with technical artifacts resulting also in organizational and process changes. This effect was frequently observed during previous projects and can be regarded as almost inherent to the introduction of new technical artifacts in mission-driven organization [51].

\subsection{Service Design and Multi-Aspect Analysis}

\subsubsection{Definition Unmanned Aerial Vehicles (UAV)}

Since various terms are used for UAVs such as drones, unmanned aircraft system (UAS), remotely piloted aircraft (RPA), remotely piloted aircraft system (RPAS), etc. each of which is slightly different, a closer look needs to be taken at the technical and legal regulations [52]. The term drones is widespread and is commonly used in Germany, Switzerland and France [53]. The Joint Air Power Competence Center (JAPCC) is a NATO accredited center of excellence and it defines an unmanned aircraft (UA) as 'an aircraft which is designed to operate with no human pilot on board and which does not carry personnel' [54] (p. 22). Drones come in all shapes and sizes and they can be used in many different systems and for many different purposes, as for instance for leisure and hobby purposes by private persons but also in highly advanced systems in commercial and military areas. They thus show considerable variety. However, all drones have the point in common that they are heavier-than-air craft. Furthermore, they can be categorized by different attributes. Size is one of the major attributes, as drones can be classified beginning with micro UAVs of less than $2 \mathrm{~kg}$ weight and a normal operating altitude of up 
to $200 \mathrm{ft}$ ending with UAVs for strike and combat with an unlimited mission radius and a normal operating altitude of up to $65,000 \mathrm{ft}$, which are also known as predator UAVs. Another criterion is the design as fixed-wing aircraft or rotor-craft. Fixed-wing UAVs have advantages in terms of speed, endurance, range, and robustness. In contrast rotor-craft have the capability to hover, they can land and take-off from small base locations and are more flexible [55]. UAVs are already in use in different scenarios. For example, German police forces have been using UAVs to observe hooligans and urban areas [56]. Other applications could be the usage as a communications-relay device, in search and rescue missions [55].

The legal situation under which UAVs operate is complex and not completely clear as yet due to the fragmented regulatory framework existing at the present time. The rules differ across the European Union (EU). The following section provides details about the legal aspects for the case at hand.

\subsubsection{Legal and Business Aspects}

When discussing legal aspects of the use of UAVs for mountain search and rescue missions one must distinguish between status and use of a UAV as such on the one hand and the use of its payload within the legal limits of alpine police missions on the other hand. Until recently UAVs $<150 \mathrm{~kg}$ were subject to national regulation only; in July 2018 EU Regulation 2018/1139 transferred the regulatory competence from the member states to the Union. Two further regulations determine detailed rules on technical aspects and on the operation of UAVs. The latter has adopted a risk-based approach, distinguishing between 'open', 'specific' and 'certified' categories based on mass and mission of the UAV. The system includes a comprehensive exemption for all kind of equipment used by the military, by police forces, by customs services, and by all kinds of rescue organizations. Consequently, Member States can choose whether to continue to apply national rules or decide autonomously to apply the forthcoming EU rules. Most likely Austria will opt for the latter. Turning now to the payload used and data collected during mountain search and rescue missions, one must bear in mind a crucial difference between private activities and state activities: While private individuals may do anything which is not forbidden by law, authorities may do nothing unless expressly empowered to. As alpine police forces come under the second group they must strictly observe the rules and limits of the Austrian Police Act ('Sicherheitspolizeigesetz', SPG) as well as those of the Austrian Data Protection Act ('Datenschutzgesetz', DSG) and the EU General Data Protection Regulation, respectively. Under these, person-related data (i.e., data which allows the identification of a particular person) may be collected and used by the police only for the purpose of countering criminal activities (which will not normally be the case under alpine search and rescue missions), with the only exception of data from real-time recording which may inevitably allow the identification of individual persons. Figure 7 provides a detailed analysis of legal aspects for the planned information service based on enhancements of the $\mathrm{V}^{2}$ value network notation [2]. As a basis a technical configuration according to the Austrian Aviation Authority using class I UAVs in the application area A and B were chosen.

Overall, no major legal problems are identified for the selected technical configuration. Furthermore, value network analysis provides evidence that the designed service meets the needs of participating actors and therefore provides a solid foundation for a viable digital innovation. 


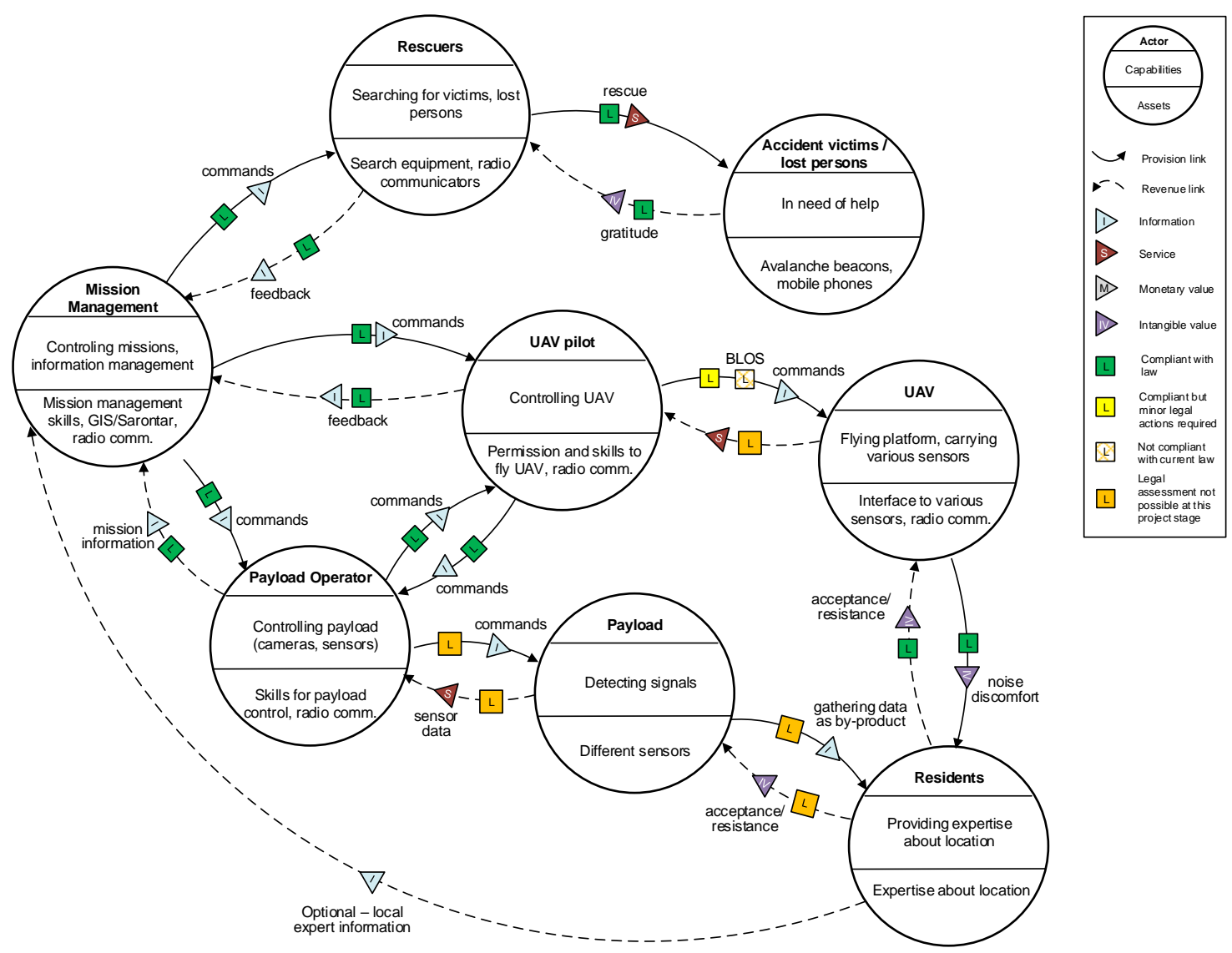

Figure 7. Legal assessment combined with value exchange relations of the planned information service.

\subsubsection{Organizational and Operations Aspects}

The key to successful creation of new information services for large organizations such as the Federal Police is the integration of these new units into the existing backbone infrastructure as also a practical operations concept for end users. This also influences the technology selection. In our case, class I UAVs were selected due to their easy and uncomplicated operational and architectural aspects. According to the classification (see [48]) into backbone, branches and leaves components, UAVs can be assigned to the leaves class. Since these components are relatively cheap and undergo extremely short technology life-cycles, they need to be easily replaceable via standardized system interfaces.

In the operational context, the selected UAVs need to be easily transportable, relatively cheap due to the risk of loss in harsh environments and suitable for use by controllers who will need to have completed affordable training courses. All these aspects can best be met by class I UAVs in application area A and B.

Since, use cases and utility levers and the technical, legal, and organizational aspects have now been analyzed and mapped, the detailed technical engineering and consequently implementation of the designed information service can start. The proposed improvement concepts need to be included in existing mission management systems and organizational and process aspects need to be adapted to this digital innovation. This process corresponds to the reconfiguration phase of dynamic capabilities theory [44]. Although the engineering and implementation phases, together with the deployment of the service are important phases, they are beyond the scope of this article and therefore not described in detail here. 


\section{Results and Discussion}

In this paper, we present a framework that provides guidance on how to implement the dynamic capabilities needed for business model and service innovation within an organization. We introduce a method to combine technology and use-case sensing with the ultimate aim of creating innovative artifacts for organizations, which is based on a design science research approach. Following this approach, the framework was used and tested in practice. A case from the public-safety domain served as an example to show the implementation of this method by analyzing and designing an information system with critical social and organizational aspects. IT experts concerned with the management of information systems of an organization may profit from the presented framework in various aspects. In general, the framework supports innovation processes by providing guidance in technology abstraction and human-centered service design. It provides tools and holistic concepts to facilitate the generation of novel services grounded on a socio-technical system context. In case the IT management is embedded into a formal IT governance framework such as ITIL [57], the presented framework adds to the service design [58] aspect with its technology- and process-induced innovation concepts. IT experts in particular may benefit from the technology abstraction process and the focus on the global optimization of the socio-technical system facilitated by the tools presented. Consequently, the framework may also positively influence the formal continual service improvement processes [59] in information systems management. From a general management point of view, the framework complements existing top-down BMI approaches by providing an informed base of knowledge for user's jobs and processes resulting in the design and implementation of innovative digital artifacts. The framework facilitates a strong tie between process owners and technology owners and therefore creates a strong axis between users and service providers in a socio-technical context.

As a proof of concept and a very first step towards validation, we have chosen a case study in a very rich environment: public safety and security where we applied UCTM at all levels. In addition to a generic description of the framework, we presented tools specifically targeted to public-safety needs in the above case study.

The framework proved useful for revealing relevant areas of improvement, both anticipated and unexpected ones. Due to the ambidextrous approach, it was possible to identify levers in a technology-independent way and appropriate tools, which are not limited to a given set of possibilities. This holistic investigation of the existing socio-technical system ensures joint optimization of the technological and social aspects.

Building blocks of the framework have already proved to be a good guidance for different types of projects ranging from health care to public safety and production and maintenance. A major reason for its successful application in these domains is the clear and systematic structure of the framework, which improves understanding and transparency for stakeholders throughout the entire service design process. Furthermore, related tools ensure practicability in the course of the different project phases and support a systematic documentation. Very helpful during the case study was the strict separation between technology and demands. This intended separation also fosters the independent creation of a stack of technology-based functions and a stack of process improvement levers. Both stacks can be updated in the future. This feature enables a continuous system improvement process that can capture future developments in needs and technology innovation.

With respect to re-using process and technology knowledge, UCTM provides the possibility to build domain-specific and domain-independent stacks, which could be used for front-loading of new projects, similar to software templates and repositories. Another advantage of the UCTM framework is the transferability of existing knowledge, especially with respect to the technology-driven part. Once a technology is analyzed according to the proposed approach, the gathered tools and functions can be reused for different applications and use cases. Moreover, cross-domain learnings can be facilitated. For instance, the technological insights in the field of augmented reality devices have already been transferred without limitations from health care to maintenance in production. 
Building blocks of the presented framework have been created and validated in multiple domains during previous projects in the areas of health care, public safety, and automotive production. Nevertheless, a methodological comparison of the applicability in these domains has not yet taken place. Despite the insights gained and the revealing of the usability of this framework in the case study conducted, further research is necessary to prove completeness and applicability. The framework is currently applied in IS research projects and provides guidance for several master student projects in various domains. Subsequently, its usefulness in other fields will be investigated and the generic applicability will also be further evaluated.

In conclusion, we can say that the proof of concept has shown that the UCTM framework is a viable, efficient, and effective framework. Especially since socio-technical systems require a holistic perspective and an ambidextrous approach to understand the emerging complexity due to the interrelation of social and technical aspects. UCTM fosters the socio-technical philosophy and combines the converging streams of human-centered and technology-driven design thinking. While the sum is greater than its parts' as Aristotle said, successful service design must nevertheless seamlessly integrate both principles.

Author Contributions: Conceptualization: W.V., D.N., B.M. and S.V.; investigation: W.V., D.N., B.M., J.B., S.S. and S.V.; methodology: W.V., D.N. and S.V.; visualization: W.V. and D.N.; project administration: B.M., J.B., W.V.; writing-original draft preparation: W.V., D.N., B.M., J.B., S.S. and S.V.; writing—review and editing: W.V., D.N., B.M., S.S. and S.V.

Funding: This research was funded by the Austrian security research program KIRAS of the Federal Ministry of Transport, Innovation and Technology (bmvit) with the grant number 854769 (SmartScout).

Acknowledgments: We would like to thank the anonymous reviewers for their highly valuable inputs. Open Access Funding by the Graz University of Technology.

Conflicts of Interest: The authors declare no conflict of interest.

\section{References}

1. Vorraber, W.; Voessner, S.; Stark, G.; Neubacher, D.; DeMello, S.; Bair, A. Medical applications of near-eye display devices: An exploratory study. Int. J. Surg. 2014, 12, 1266-1272. [CrossRef]

2. Vorraber, W.; Lichtenegger, G.; Brugger, J.; Gojmerac, I.; Egly, M.; Panzenböck, K.; Exner, E.; Aschbacher, H.; Christian, M.; Voessner, S. Designing Information Systems to Facilitate Civil-Military Cooperation in Disaster Management. Int. J. Distrib. Syst. Technol. (IJDST) 2016, 7, 22-40. [CrossRef]

3. Mumford, E. A Socio-Technical Approach to Systems Design. Requir. Eng. 2000, 5, 125-133. [CrossRef]

4. Mumford, E. The story of socio-technical design: Reflections on its successes, failures and potential. Inf. Syst. J. 2006, 16, 317-342. [CrossRef]

5. Baxter, G.; Sommerville, I. Socio-technical systems: From design methods to systems engineering. Interact. Comput. 2011, 23, 4-17. [CrossRef]

6. Walker, G.H.; Stanton, N.A.; Salmon, P.M.; Jenkins, D.P. A review of sociotechnical systems theory: A classic concept for new command and control paradigms. Theor. Issues Ergon. Sci. 2008, 9, 479-499. [CrossRef]

7. Trist, E.L. The Evolution of Socio-Technical Systems: A Conceptual Framework and an Action Research Program; Ontario Quality of Working Life Centre: Toronto, ON, Canada, 1981; p. 67.

8. Bosch, O.; Nguyen, N.; Ha, T. Can advancements in economic and managerial practice be achieved without systems thinking education as the foundation? Bus. Syst. Rev. 2014, 3, 33-53.

9. Carayon, P.; Hancock, P.; Leveson, N.; Noy, I.; Sznelwar, L.; van Hootegem, G. Advancing a sociotechnical systems approach to workplace safety-Developing the conceptual framework. Ergonomics 2015, 58, 548-564. [CrossRef]

10. Maguire, M. Methods to support human-centred design. Int. J. Hum. Comput. Stud. 2001, 55, 587-634. [CrossRef] 
11. Heath, C.; Knoblauch, H.; Luff, P. Technology and social interaction: The emergence of 'workplace studies'. Br. J. Sociol. 2000, 51, 299-320. [CrossRef]

12. Heath, C.; Luff, P. Documents and professional practice: 'Bad' organisational reasons for 'good' clinical records. In Proceedings of the 1996 ACM Conference on Computer Supported Cooperative Work, Boston, MA, USA, 16-20 November 1996; pp. 354-363.

13. Heath, C.; Jirotka, M.; Luff, P.; Hindmarsh, J. Unpacking collaboration: The interactional organisation of trading in a city dealing room. Comput. Support. Coop. Work 1994, 3, 147-165. [CrossRef]

14. Heath, C.; Luff, P. Collaboration and Control Crisis Management and Multimedia Technology in London Underground Line Control Rooms. Comput. Support. Coop. Work 1992, 1, 69-94. [CrossRef]

15. International Standardization Organization (ISO). Ergonomics of Human System Interaction-Part 210: Human-Centred Design for Interactive Systems; International Standardization Organization (ISO): Geneva, Switzerland, 2009.

16. Unger, R.; Chandler, C. A Project Guide to UX Design: For User Experience Designers in the Field or in the Making, 2nd ed.; New Riders: Berkeley, CA, USA, 2012.

17. Haberfellner, R.; de Weck, O.; Fricke, E.; Vössner, S. Systems Engineering: Grundlagen und Anwendung; Orell Füssli: Zurich, Switzerland, 2012.

18. Danneels, E. The dynamics of product innovation and firm competences. Strateg. Manag. J. 2002, 23, 1095-1121. [CrossRef]

19. Dougherty, D. A practice-centered model of organizational renewal through product innovation. Strateg. Manag. J. 1992, 13, 77-92. [CrossRef]

20. Dougherty, D. Organizing practices in services: Capturing practice-based knowledge for innovation. $S A G E$ J. 2004, 2, 35-64. [CrossRef]

21. Mager, B.; Sung, T. Special issue editorial: Designing for services. Int. J. Des. 2011, 5, 1-3.

22. Ojasalo, K.; Koskelo, M.; Nousiainen, A.K. Foresight and Service Design Boosting Dynamic Capabilities in Service Innovation. In The Handbook of Service Innovation; Agarwal, R., Selen, W., Roos, G., Green, R., Eds.; Springer: London, UK, 2015; pp. 193-212. [CrossRef]

23. Stickdorn, M.; Schneider, J. This Is Service Design Thinking: Basics, Tools, Cases; John Wiley \& Sons: Hoboken, NJ, USA, 2012.

24. Amit, R.; Zott, C. Value creation in E-business. Strateg. Manag. J. 2001, 22, 493-520. [CrossRef]

25. Schumpeter, J.A. Business Cycles; McGraw-Hill: New York, NY, USA, 1939.

26. Penrose, E. The Growth of the Firm; Basil Blackwell: Oxford, UK, 1959.

27. Wernerfelt, B. A resource-based view of the firm. Strateg. Manag. J. 1984, 5, 171-180. [CrossRef]

28. Spender, J.C. Organizational knowledge, collective practice and Penrose rents. Int. Bus. Rev. 1994, 3, $353-367$. [CrossRef]

29. Osterwalder, A.; Pigneur, Y. Business Model Generation-A Handbook for Visionaries, Game Changers, and Challengers; John Wiley \& Sons, Inc.: Hoboken, NJ, USA, 2010.

30. Osterwalder, A.; Pigneur, Y.; Bernarda, G.; Smith, A. Value Proposition Design: How to Create Products and Services Customers Want; John Wiley \& Sons: Hoboken, NJ, USA, 2014.

31. Chesbrough, H. Business Model Innovation: Opportunities and Barriers. Long Range Plan. 2010, 43, $354-363$. [CrossRef]

32. Ojasalo, K.; Ojasalo, J. Adapting business model thinking to service logic: An empirical study on developing a service design tool. In The Nordic School-Service Marketing and Management for the Future; Gummerus, J., von Koskull, C., Eds.; CERS, Hanken School of Economics: Helsinki, Finland, 2015; pp. 309-333.

33. Maurya, A. Running Lean-Iterate from Plan A to a Plan That Works; O'Reilly Media: Sebastopol, CA, USA, 2012.

34. Breuer, H.; Ketabdar, H. User-Driven Business Model Innovation-New Formats and Methods in Business Modeling and Interaction Design, and the Case of Magitact. In Proceedings of the IADIS International Conference on eSociety, Berlin, Germany, 10-13 March 2012; pp. 211-218.

35. Breuer, H. Lean venturing: Learning to create new business through exploration, elaboration, evaluation, experimentation, and evolution. Int. J. Innov. Manag. 2013, 17, 1340013-1340022. [CrossRef] 
36. Social Innovation Lab. Social Business Model Canvas. Available online: http://www. socialbusinessmodelcanvas.com/ (accessed on 16 April 2019).

37. Upward, A.; Jones, P. An Ontology for Strongly Sustainable Business Models: Defining an Enterprise Framework Compatible with Natural and Social Science. Organ. Environ. 2016, 29, 97-123. [CrossRef]

38. Dentchev, N.; Baumgartner, R.; Dieleman, H.; Jóhannsdóttir, L.; Jonker, J.; Nyberg, T.; Rauter, R.; Rosano, M.; Snihur, Y.; Tang, X. Embracing the variety of sustainable business models: Social entrepreneurship, corporate intrapreneurship, creativity, innovation, and other approaches to sustainability challenges. J. Clean. Prod. 2016, 113, 1-4. [CrossRef]

39. Rauter, R.; Jonker, J.; Baumgartner, R.J. Going one's own way: Drivers in developing business models for sustainability. J. Clean. Prod. 2017, 140, 144-154. [CrossRef]

40. Breuer, H.; Lüdeke-Freund, F. Values-based network and business model innovation. Int. J. Innov. Manag. 2017, 21, 1750028. [CrossRef]

41. Jones, P.; Upward, A. Caring for the future: The systemic design of flourishing enterprises. In Proceedings of the RSD3, Third Symposium of Relating Systems Thinking to Design, Oslo, Norway, 15-17 October 2014; Volume 3, pp. 1-8.

42. Joyce, A.; Paquin, R.L. The triple layered business model canvas: A tool to design more sustainable business models. J. Clean. Prod. 2016, 135, 1474-1486. [CrossRef]

43. Max-Neef, M.; Dlizalde, A.; Hopenhayn, M. Human Scale Development: Conception, Application and Further Reflections; Apex Press: Lanham, MD, USA, 1991.

44. Teece, D.J. Explicating dynamic capabilities: The nature and microfoundations of (sustainable) enterprise performance. Strateg. Manag. J. 2007, 28, 1319-1350. [CrossRef]

45. Osterwalder, A.; Pigneur, Y. An e-business model ontology for modeling e-business. In Proceedings of the 15th Bled Electronic Commerce Conference, Bled, Slovenia, 17-19 June 2002; pp. 17-19.

46. Hevner, A.R.; March, S.T.; Park, J.; Ram, S. Design Science in Information Systems Research. MIS Q. 2004, 28, 75-105. [CrossRef]

47. Vössner, S.; Lichtenegger, G. Design Patterns for Information Systems for Public Protection and Disaster Relief. In Operations Research Colloquium; Graz University of Technology: Graz, Austria, 2011.

48. Vorraber, W.; Lichtenegger, G.; Neubacher, D.; Voessner, S. Designing sustainable information systems for organizations operating in safety critical environments. In Proceedings of the IEEE Eighth International Conference on Software Testing, Verification and Validation Workshops (ICSTW), Graz, Austria, 13-17 April 2015; pp. 1-5. [CrossRef]

49. Vidgen, R.; Braa, K. Balancing Interpretation and Intervention in Information System Research: The Action Case Approach. In IFIP-The International Federation for Information Processing; Lee, A.S., Liebenau, J., DeGross, J.I., Eds.; Springer: Boston, MA, USA, 1997; pp. 524-541. [CrossRef]

50. Dudek, K. Die Besondere Aufbauorganisation. Bewältigung komplexer Lagen (Teil 1). SIAK Journal Zeitschrift für Polizeiwissenschaft und Polizeiliche Praxis 2007, 1, 14-28.

51. Lichtenegger, G.; Vorraber, W.; Gojmerac, I.; Sporer, A.; Brugger, J.; Exner, E.; Aschbacher, H.; Christian, M.; Voessner, S. Identification of information gaps in civil-military cooperation in disaster management. In Proceedings of the 2015 2nd International Conference on Information and Communication Technologies for Disaster Management (ICT-DM), Rennes, France, 30 November-2 December 2015; pp. 122-129.

52. Klauser, F.; Pedrozo, S. Power and space in the drone age: A literature review and politico-geographical research agenda. Geogr. Helv. 2015, 70, 285-293. [CrossRef]

53. Zubeldia, O. Histoire Des Drones; Perrin: Paris, France, 2012.

54. Joint Air Power Competence Centre. Strategic Concept of Employment for Unmanned Aircraft Systems in NATO; Joint Air Power Competence Centre: Kalkar, Germany, 2010.

55. Clarke, R. Understanding the drone epidemic. Comput. Law Secur. Rev. 2014, 30, 230-246. [CrossRef]

56. Finn, R.L.; Wright, D. Unmanned aircraft systems: Surveillance, ethics and privacy in civil applications. Comput. Law Secur. Rev. 2012, 28, 184-194. [CrossRef]

57. Cannon, D.; Hunnebeck, L.; Lloyd, V.; Orr, A.; Rance, S.; Rudd, C.; Steinberg, R. ITIL Service Strategy; The Stationery Office Ltd.: Norwich, UK, 2011. 
58. Hunnebeck, L.; Cannon, D.; Lloyd, V.; Orr, A.; Rance, S.; Steinberg, R.; Wheeldon, D. ITIL Service Design; The Stationery Office Ltd.: Norwich, UK, 2011.

59. Lloyd, V.; Cannon, D.; Hunnebeck, L.; Orr, A.; Rance, S.; Rudd, C.; Steinberg, R. ITIL Continual Service Improvement; The Stationery Office Ltd.: Norwich, UK, 2011.

(C) 2019 by the authors. Licensee MDPI, Basel, Switzerland. This article is an open access article distributed under the terms and conditions of the Creative Commons Attribution (CC BY) license (http:/ / creativecommons.org/licenses/by/4.0/). 